\title{
Biliary spillage a new prognostic factor in gallbladder cancer?
}

\author{
Xabier de Aretxabala \\ Department of Surgery, Clínica Alemana de Santiago, Santiago, Chile \\ Correspondence to: Xabier de Aretxabala. Department of Surgery, Clínica Alemana de Santiago, Santiago, Chile. Email: xdearetxabala@alemana.cl. \\ Comment on: Horkoff MJ, Ahmed Z, Xu Y, et al. Adverse Outcomes After Bile Spillage in Incidental Gallbladder Cancers: A Population-based Study. \\ Ann Surg 2019. [Epub ahead of print].
}

Submitted Jul 11, 2019. Accepted for publication Jul 19, 2019.

doi: 10.21037/hbsn.2019.07.22

View this article at: http://dx.doi.org/10.21037/hbsn.2019.07.22

Gallbladder cancer is considered a rare disease associated with a dismal prognosis (1-3). However, since the irruption of laparoscopic cholecystectomy, incidental cases have increased and prognosis improved. The main reason for this improvement is the detection of unapparent tumors corresponding to mucosal and muscular lesions. Although laparoscopy has been associated with faster recovery and shorter hospital stay, the effect that gallbladder rupture and subsequent bile spillage on the prognosis of patients harboring an incidental gallbladder cancer is not completely understood $(4,5)$.

Since the beginning of laparoscopic cholecystectomy, cases report of patients who underwent laparoscopic cholecystectomy and developed peritoneal and scar recurrences were described (6). Because of the above, laparoscopy was considered a contraindication in cases in whom a gallbladder cancer is suspected.

Unfortunately, the lower incidence of gallbladder cancer in the majority of countries did not allow to get a large number of patients to study this problem (1).

The manuscript written by Horkoff et al. studied the effect of bile spillage during cholecystectomy on prognosis (7). To accomplish the above, the authors conducted a retrospective study analyzing a large cohort of cholecystectomies performed between 2001 and 2015 in Alberta Canada. In spite of the number of cholecystectomies, only 82 cases of incidental gallbladder cancer fulfilled the requirements to be included in the study. Spillage was divided into three different types: (I) unintentional perforation, (II) intraoperative cholangiogram, and (III) Intentional decompression. It is supposed that in cholangiogram and intentional decompression, leaks were controlled and of lesser magnitude. On the contrary, in unintentional perforations occurred during the cholecystectomy, spilled was uncontrolled and sometimes associated with larger amounts of bile and even stones.

From the analysis of the results, it is interesting to highlight the number of patients with unintentional gallbladder perforation. According to different authors, the chance of gallbladder wall perforation ranges between $13 \%$ and $40 \%$ during an elective cholecystectomy $(6,8,9)$. In this series, $39 \%$ of cholecystectomies were associated with unintentional spillage.

The impact of bile spillage was studied according to different variables such as re-resection rate, peritoneal carcinomatosis, and survival. Bile spillage was reported to be an independent factor related to the re-resection rate. The same tendency was observed when peritoneal carcinomatosis was studied. Thirteen of 14 patients who developed peritoneal disease occurred in the patients with spillage. Finally, concerning disease-free survival, spillage was also associated with a worse prognosis.

In our center, we did the same study, and the conclusions were almost similar (unpublished data). In our study, the spillage magnitude was more important that the only spillage presence. In this sense, those patients with spillage including stones or having wall necrosis associated with spillage were related to a worse prognosis.

The main limitation of this type of study is the retrospective nature. Further, the low incidence of the disease means to include different centers during a long period of time. Also, the authors describe that some operative charts were not found for review. In the same way, probably not all leaks were reported adding additional biases. However, in spite of the previous limitations, bile spillage as results of cholecystectomy should be considered 
as a potential prognosis factor in patients with incidental tumors. Although this disease is considered a rare disease, the potential effect of this event must alert surgeons dealing with patients harboring biliary pathology. The authors state that some findings such as irregular wall thickening, enlarged lymph nodes or infiltration into the liver can raise suspicious and make the surgeon to avoid any attempt to decompress the gallbladder, I agree with the above however we have also to take into account that many of incidental gallbladder tumors are completely unapparent and unsuspected. Because of the above, gentle management of gallbladder during cholecystectomy avoiding the possibility of wall perforation should be in the mind of surgeons during the procedure. This advice is mainly important in areas where gallbladder cancer has a higher incidence. On the other hand, the recognition of spillage as prognostic factor raises the question about its management in cases of incidental tumors.

\section{Acknowledgments}

None.

\section{Footnote}

Conflicts of Interest: The author has no conflicts of interest to declare.

Ethical Statement: The authors is accountable for all aspects of the work in ensuring that questions related to the accuracy or integrity of any part of the work are appropriately investigated and resolved.

Cite this article as: de Aretxabala X. Biliary spillage a new prognostic factor in gallbladder cancer? HepatoBiliary Surg Nutr 2019;8(5):537-538. doi: 10.21037/hbsn.2019.07.22

\section{References}

1. Stinton LM, Shaffer EA. Epidemiology of gallbladder disease: cholelithiasis and cancer. Gut Liver 2012;6:172-87.

2. Wistuba II, Gazdar AF. Gallbladder cancer: lessons from a rare tumor. Nat Rev Cancer 2004;4:695-706.

3. de Aretxabala X, Roa I, Burgos L, et al. Gallbladder cancer: an analysis of a series of 139 patients with invasion resticted to the subserosal layer. J Gastrointest Surg 2006;10:186-92.

4. Søreide K, Guest RV, Harrison EM, et al. Systematic review of management of incidental gallbladder cancer after cholecystectomy. Br J Surg 2019;106:32-45.

5. Tantia O, Jain M, Khanna S, et al. Incidental carcinoma gall bladder during laparoscopic cholecystectomy for symptomatic gall stone disease. Surg Endosc 2009;23:2041-6.

6. Z' graggen K, Birrer S, Maurer CA, et al. Incidence of port site recurrence after laparoscopic cholecystectomy for preoperatively unsuspected gallbladder carcinoma. Surgery 1998;124:831-8.

7. Horkoff MJ, Ahmed Z, Xu Y, et al. Adverse Outcomes After Bile Spillage in Incidental Gallbladder Cancers: A Population-based Study. Ann Surg 2019. [Epub ahead of print].

8. Ahmad J, Mayne AI, Zen Y, et al Spilled gallstones during laparoscopic cholecystectomy. Ann R Coll Surg Engl 2014;96:e18-20.

9. Lee JM, Kim BW, Kim WH, et al. Clinical implication of bile spillage in patients undergoing laparoscopic cholecystectomy for gallbladder cancer. Am Surg 2011;77:697-701. 